\title{
Estimation of the Water Temperature Influence on Direct Evaporative Cooler Operation*
}

\author{
Dr. E. D. Rogdakis ${ }^{1}$, Dr. I. P. Koronaki ${ }^{2}$, D. N. Tertipis ${ }^{3 * *}$ \\ National Technical University of Athens, Faculty of Mechanical Engineering, Laboratory of Applied Thermodynamics \\ 9, Iroon Polytechniou Str., 157 80, Zografou (NTUA Campus) \\ E-mail: ${ }^{1}$ rogdemma@central.ntua.gr; ${ }^{2}$ koronaki@central.ntua.gr; ${ }^{3}$ dtert@ mail.ntua.gr
}

\begin{abstract}
In the present paper a study is conducted of the mass and heat transfer phenomena which rule the function of a direct evaporative cooler. A comprehensive mathematical model is developed, which is based on the latent and sensible heat transfer and can predict the efficiency of such a cooler under any circumstances of operation and water supply. As a development of the existing simulation models of direct evaporative coolers, the model presented here is general, as far as the temperature of the supply water is concerned as an independent parameter. In addition, direct evaporative cooling is evaluated according to its efficiency, the quality of produced air and the specific consumption of water while working in Mediterranean climates.
\end{abstract}

Keywords: Thermodynamics; direct evaporative cooling; cooling efficiency; cooling capacity; specific water consumption

\section{Introduction}

Evaporative cooling is based on the phenomenon, according to which when a fluid evaporates, it absorbs latent heat from its environment. A common application of evaporative cooling are cooling towers, where a cloud of moisture evaporates absorbing heat from water drops, which are, therefore, forced to cool. By using air instead of water, the product of the procedure could be cold air, which can be applied in residential or commercial airconditioning.

The simplest (in terms of construction) form of evaporative cooling is the direct evaporative cooler. The basic parts of such a cooler are shown in Figure 1 below.

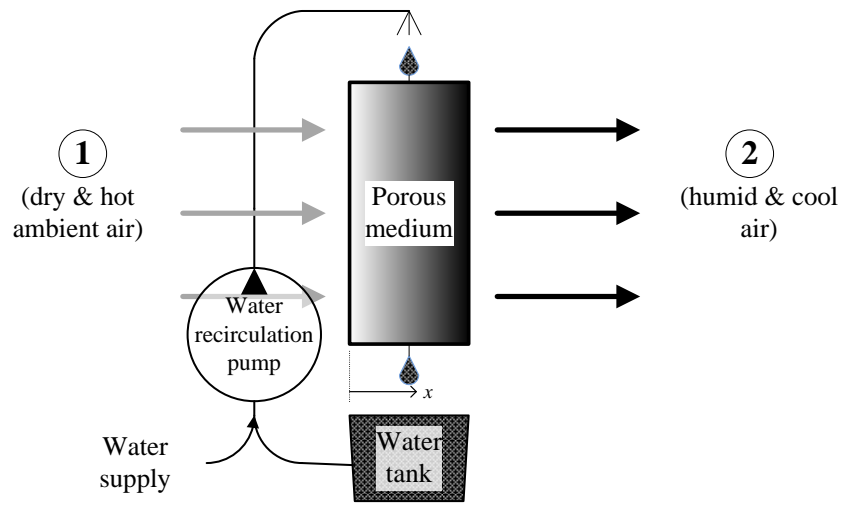

Figure 1. Configuration of a direct evaporative cooler.

The hot and arid ambient air is led to a porous pad, which is kept wet by water of temperature $t_{\mathrm{w}}$. As the air comes through the pad, it superficially contacts the water which forms a thin film surface over the pad. Given that the air is dry, it causes the evaporation of the water, which is received as latent heat $q_{l}$. Due to the fact that the cooler is fully isolated from its environment, in the ideal case that the wet bulb temperature of the ambient air $t_{1, \mathrm{wb}}$ is the same as the water temperature $t_{\mathrm{w}}$, the air enthalpy remains the same, and therefore, any increase in the latent energy load (due to the increase in the air humidity $W_{2}-W_{1}$ ) is "balanced" by the simultaneous reduction of the sensible energy load, which is understood by the reduction of the dry bulb temperature of the air $t_{2, \mathrm{db}}$. It is clear that after such a thermodynamic procedure (also known as adiabatic saturation), the product air contains a significant amount of moisture (theoretically the product air can be saturated; in fact, its relative humidity approaches $\varphi_{2}=85 \%$ ).

It is clear that the driving force of the evaporation is the humidity difference between the incoming air and the airwater interface, where the air could be considered saturated; consequently, the drier the supply air, the bigger the cooler capacity. The size which quantifies the efficiency of such a cooler (and of evaporative coolers, in general) is its wetbulb efficiency and can be defined as follows (if there is no subscript, the symbol $t$ refers to dry-bulb temperature):

$\eta=\frac{t_{1}-t_{2}}{t_{1}-t_{1, w b}\left(t_{1}, \phi_{1}\right)}$

A typical direct evaporative cooler can easily achieve efficiency of above $80 \%$. Given that evaporative systems consist of heat and mass exchanger(s), a Coefficient of Performance (COP) cannot be defined, as there is no cooling machine (vapour compression or absorption etc.); the only electrical consumption of evaporative systems refers to pumps, fans, electronic controllers and is generally negligible.

The main advantages of evaporative coolers are, therefore, the remarkably low electric power consumption (and consequently, their small dependence on the electricity network and the negligible burden to them, in contrast to

${ }^{*}$ This paper is an updated version of a paper published in the CPOTE 12 proceedings. It is printed here with permission of the authors and organizers. 
the compatible power consuming air-conditioning units) and the use of water as a totally harmless working media (instead of dangerous refrigerants). One of their disadvantages is the consumption of water, which might not be in abundance or of economical interest in its production.

\section{Mathematical Model of Direct Evaporative Coolers \& Assumptions}

The performance and efficiency of evaporative coolers has been the object of investigation of numerous scientific groups during the past decades and the exported results are quite interesting most recently, papers were published by Fouda \& Melikyan (2011), Kachhwaha \& Prabhakar (2010), Lazzarin (2007), Wu, Huang \& Zhang, (2009), Finlay \& Harris (1984). The approaches adopted in these papers are based on analyzing heat and mass transfer phenomena or on the balance between sensible and latent energy load.

For purposes of simplification, the supply water is usually considered to have a temperature equal to the wet bulb temperature of the incoming air (nominal supply condition). The purpose of the analysis in the following paragraph is to actually modify that restriction and create a mathematical model where the temperature of the supply water will be yet another inlet data, i.e. the model will be independent of the water temperature. Should the last one be different from the wet bulb temperature of the incoming air, then during the contact of the air with the wet surface, these two temperatures would tend to equalize.

The assumptions upon which the energy analysis will be based are the following: (1) water is diffused/distributed on the pad uniformly, at a steady temperature and is unlimitedly available; (2) moistening of the pad is permanent and always capable of covering any humidity need; (3) for given inlet circumstances and given pad configuration, the heat $k_{\mathrm{h}}$ and mass $k_{\mathrm{m}}$ transfer factors are kept constant throughout the pad; (4) the Lewis number is considered to be equal to one; (5) the phenomenon is taking place in one dimension and the pad is thermally isolated; (6) the pressure fall of the air as it passes through the pad can be ignored.

\section{Development of Mathematical Model}

At a random position $x$ away from the pad inlet, a vertical to the airflow cross section is taken, as shown in Figure 2.

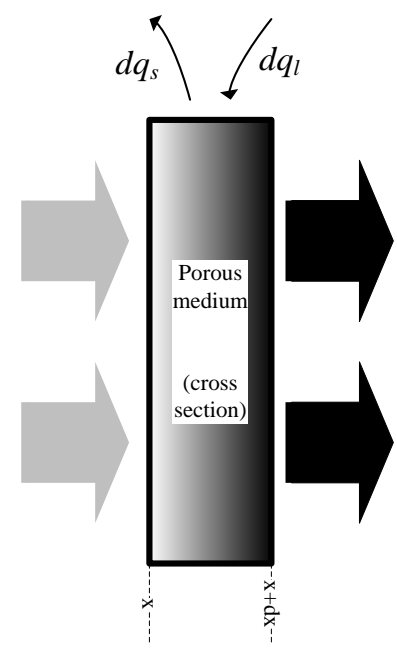

Figure 2. Cross section $x$.
At this cross section, the mass flow of the air is $m$ and its inlet and outlet enthalpies are $h_{\mathrm{a}}$ and $h_{a}+d h_{a}$, respectively, so the enthalpy exchange, in terms of sensible and latent energy, is given by the following equation.

$$
\begin{aligned}
& m_{a} \cdot h_{a}+d q_{l}-d q_{s}=m_{a} \cdot\left(h_{a}+d h_{a}\right) \\
& \Rightarrow m_{a} \cdot d h_{a}=d q_{s}-d q_{l}
\end{aligned}
$$

The wet air enthalpy is the sum of the dry air and the moisture enthalpy terms:

$h_{a}=c_{p, a} \cdot t_{a}+W \cdot\left(c_{p, s a t} \cdot t_{a}+r\right)$

where $r$ stands for the water evaporation heat. The differential of equation ( 3 ) is equal to:

$$
\begin{aligned}
& d h_{a}=c_{p, a} \cdot d t_{a}+d c_{p, a} \cdot t_{a}+d W \cdot\left(c_{p, s a t} \cdot t_{a}+r\right) \\
& +W \cdot\left(c_{p, s a t} \cdot d t_{a}\right)
\end{aligned}
$$

Since the specific heat of air may be considered steady, Eq. (4) can be written as:

$d h_{a}=c_{p, a} \cdot d t_{a}+d W \cdot\left(c_{p, s a t} \cdot t_{a}+r\right)+W \cdot c_{p, s a t} \cdot d t_{a}$

The sensible heat load exchanged between the air and the wet surface is calculated by the following simple equation:

$d q_{s}=A_{w} \cdot k_{h} \cdot\left(t_{a}-t_{w}\right) d x$

where $k_{h}\left[\mathrm{~W} / \mathrm{m}^{2} \mathrm{~K}\right]$ is for the heat transfer factor and $A_{w}$ for the wet surface. The latent heat load is defined by the humidity exchange:

$$
d q_{l}=d m_{w} \cdot h_{s t}=\left(m_{a} \cdot d W\right) \cdot\left(c_{p, s a t} \cdot t_{w}+r\right)
$$

The equation above includes the minimum humidity ratio change in the section $d x$ (see Fig. 2), which is calculated by the expression:

$$
\begin{aligned}
& \frac{d W}{d x}=\frac{A_{w} \cdot k_{m}}{m_{a}} \cdot\left[W_{s a t}\left(t_{w}\right)-W\right] \\
& \Rightarrow d W=\frac{A_{w} \cdot k_{m}}{m_{a}} \cdot\left[W_{s a t}\left(t_{w}\right)-W\right] d x
\end{aligned}
$$

where $k_{\mathrm{m}}\left[\mathrm{kg} / \mathrm{m}^{2} \mathrm{~s}\right]$ corresponds to the mass transfer coefficient, while the saturated-state humidity ratio is given as a function of temperature (see Perry's Chemical Handbook, 2008):

$$
W_{\text {sat }}\left(t_{w}\right)=\exp \left(\begin{array}{l}
73.649-\frac{7258.2}{t_{w}+273.15}- \\
-7.3037 \cdot \ln \left(t_{w}+273.15\right)+ \\
+4.1653 \cdot 10^{-6} \cdot\left(t_{w}+273.15\right)^{2}
\end{array}\right)
$$

The Lewis number is calculated according to the following equation (Papaefthimiou, 2004): 


$$
L e=\frac{k_{h}}{\bar{c}_{p} \cdot k_{m}}=\frac{k_{h}}{\left(c_{p, a}+W \cdot c_{p, s a t}\right) \cdot k_{m}}
$$

By replacing equations 5, 6 and 7 in Eq. (2), the result is:

$$
\begin{aligned}
& m_{a} c_{p, a} d t_{a}+m_{a} d W\left(c_{p, s a t} t_{a}+r\right)+m_{a} W c_{p, s a t} d t_{a} \\
& =A_{w} \cdot k_{h} \cdot\left(t_{a}-t_{w}\right) d x+m_{a} d W\left(c_{p, s a t} t_{w}+r\right)
\end{aligned}
$$

and by simplifying this relationship:

$$
\begin{aligned}
& m_{a} d t_{a}\left(c_{p, a}+W c_{p, s a t}\right)= \\
& A_{w} k_{h}\left(t_{a}-t_{w}\right) d x-m_{a} \frac{d W}{d x} c_{p, s a t}\left(t_{a}-t_{w}\right) d x
\end{aligned}
$$

In this way, the temperature distribution along the cooling device (as a function of dimensionless length $x$ ) is described to the following differential equation:

$$
\frac{d t_{a}}{d x}=\frac{1}{c_{p, a}+W \cdot c_{p, s a t}} \cdot\left(\frac{k_{h} \cdot A_{w}}{m_{a}}-c_{p, s a t} \frac{d W}{d x}\right) \cdot\left(t_{a}-t_{w}\right)
$$

By solving the system of equations $8,10,11$ and 12 in the space from $x=0$ to $x=1$, the air temperature and humidity ratio are calculated.

As has been told, the fluid dynamic term of the problem does not affect the calculations, because the flow is considered to be laminar and of constant pressure. In this way, the energy analysis of direct evaporative coolers is completely independent of the configuration of the porous medium and of the way the air passes through it.

In order to confirm the accuracy of the mathematical model at the nominal supply condition (i.e. the supplied water temperature is equal to ambient air wet-bulb temperature), experimental data were used from the paper of Camargo, Ebinuma \& Silveira (2005), at which a parametric evaluation of a direct evaporative cooler is described. For the execution of the mathematical model, MathCAD software was used (in specific the differential equations system was solved by the method Runge - Kutta) and the purpose of the comparison is to confirm the quality of the direct evaporative cooler model, given specific climate data. The Lewis number is considered to be equal to 1 (actually, its value varies between 0.992 and 1.006, according Bosnjakovic correlation (Erens \& Dreyer, 1991), but, for common evaporative devices, it is generally accepted as being equal to 1); the calculation of the heat transfer factor was based upon data from the same paper, which led to an exposal relationship between the factor and the mass flow of the cooler used in this paper:

$$
k_{h}\left(m_{a}\right)=117.18 \cdot m_{a}^{0.81}
$$

The measured data, taken from the work of Camargo et al. (2005) (temperature, wet-bulb temperature, relative humidity and air volume), as well as the calculated data, based on the same conditions and performed by the analytical model are shown in Figure 3. The dimensions of the pad are $610 \mathrm{~mm} \times 335 \mathrm{~mm} \times 152 \mathrm{~mm}$ and its porosity (i.e. the ratio of the internal configuration surface to the external volume of the pad) equals to $370 \mathrm{~m}^{-1}$. The experimental results are compared to the model, assuming that the cooler is supplied with water of nominal temperature.

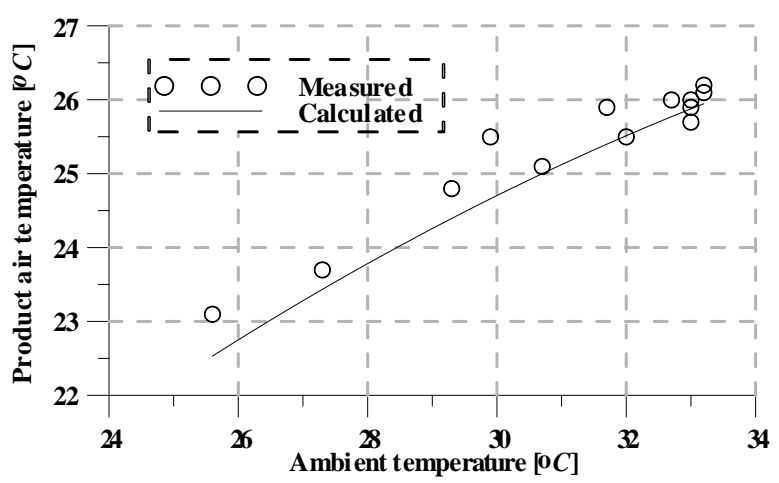

Figure 3. Comparison of calculating model results and experimental data.

From this comparison it can be derived that the average error of the product air temperature predictions is about $1.05 \%$, therefore, the model describes quite satisfactorily the cooler operation. A device of the same dimensions and characteristics will be used in the following paragraphs in order to execute several and comparable cooler operation scenarios.

\section{Application of Direct Evaporative Cooling in Real Circumstances}

As previously mentioned, due to their mode of operation evaporative coolers can provide air of satisfactory low temperature while working in dry climates. The reason is that the more humid the air, the less the difference between the dry and wet bulb temperatures [see Eq. (1)], and the cooling capacity.

Table 1. Ambient Air Conditions.

\begin{tabular}{cccc}
\hline $\begin{array}{c}\mathbf{t}_{\mathbf{1}} \\
{\left[{ }^{\boldsymbol{C}} \boldsymbol{C}\right]}\end{array}$ & $\begin{array}{c}\boldsymbol{\varphi}_{\mathbf{1}} \\
{[\mathbf{\%}]}\end{array}$ & $\begin{array}{c}\mathbf{W}_{\mathbf{1}} \\
{\left[\mathbf{k g}_{\mathbf{w}} / \mathbf{k g}_{\mathbf{d a}}\right]}\end{array}$ & $\begin{array}{c}\mathbf{t}_{\mathbf{1 , w b}} \\
{\left[{ }^{\boldsymbol{}} \mathbf{C}\right]}\end{array}$ \\
\hline 34.3 & 28.2 & 0.0095 & 20.57 \\
34.6 & 27.8 & 0.0095 & 20.68 \\
34.7 & 27.3 & 0.0094 & 20.62 \\
34.8 & 27.4 & 0.0095 & 20.72 \\
35.0 & 27.2 & 0.0095 & 20.80 \\
35.1 & 27.3 & 0.0096 & 20.90 \\
35.2 & 26.9 & 0.0095 & 20.86 \\
35.3 & 26.6 & 0.0095 & 20.85 \\
35.6 & 26.6 & 0.0096 & 21.06 \\
35.9 & 26.0 & 0.0096 & 21.10 \\
36.2 & 24.8 & 0.0093 & 20.98 \\
36.3 & 24.6 & 0.0093 & 20.99 \\
36.4 & 24.7 & 0.0094 & 21.09 \\
36.7 & 24.2 & 0.0093 & 21.15 \\
36.9 & 23.6 & 0.0092 & 21.11 \\
37.2 & 24.2 & 0.0096 & 21.48 \\
37.4 & 23.5 & 0.0094 & 21.41 \\
\hline
\end{tabular}

Mediterranean climates are ideal for applying evaporative cooling systems, since their main characteristics are low humidity and high temperatures during the summer season. The present paragraph will examine the ability of an evaporative cooler, like the one analyzed above, to meet the cooling demand in Mediterranean climates. For purposes of evaluation ambient air measurements were used, typical of the summer Mediterranean conditions (Table 1). As mentioned above, the main goal of the energy analysis of a direct evaporative cooler is an estimation of its efficiency, not only under 
various temperature conditions, but also at various supply water temperatures. Thus, the efficiency will be examined for temperatures $\mathrm{t}_{\mathrm{w}}=\mathrm{t}_{1, \mathrm{wb}}$ (nominal supply condition), $\mathrm{t}_{\mathrm{w}}=$ $\mathrm{t}_{1, \mathrm{wb}} \pm 0.5^{\circ} C, \mathrm{t}_{\mathrm{w}}=\mathrm{t}_{1, \mathrm{wb}} \pm 1.0^{\circ} \mathrm{C}$ (5 cases in total). Notice must be taken of the fact that the humidity ratio is kept almost constant during all measurements of the ambient air (as clearly shown in Table 1, which facilitates the processing of the results).

Figure 4 shows the simulation results for the 5 cases of supply water temperatures.

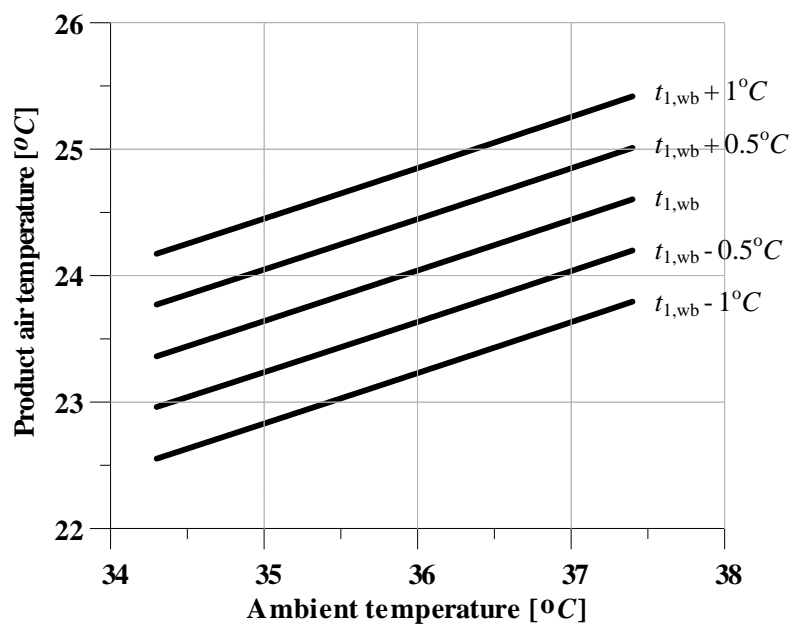

Figure 4. Product air temperature.

The air temperature at the outlet of the cooler tends to increase along with the ambient temperature, only at a slower rate (according to other bibliographic cases too); that means that a rise in ambient temperature by $1^{\circ} \mathrm{C}$ is not accompanied by an increase of the cooled air by $1^{\circ} C$, but only much less. The effect of the cooler supply with water cooler or hotter than the ambient air wet bulb temperature is also clarified: specifically, for water cooler by $1{ }^{\circ} \mathrm{C}$ from the nominal, the air ends up cooler by $0.81^{\circ} \mathrm{C}$. on the other hand, if the cooler is supplied with water hotter by $1^{\circ} \mathrm{C}$ than the nominal, then the air will be hotter by $0.81^{\circ} \mathrm{C}$ compared to the air product at the nominal supply conditions.

The reason that temperature differences higher than $1.0^{\circ} \mathrm{C}$ are not examined is that, although the water temperature within direct evaporative coolers is considered to be constant, if the water temperature is different from the ambient wet bulb temperature, not only is the air cooled, but also the water. Additionally, the wet pad behaves as a "thermal mass", the temperature of which approaches the theoretically minimum possible temperature (equal to the ambient wet bulb temperature), so the water cannot be affected by the pad's temperature. Thus, the term "water temperature" practically means the temperature of the wet pad, which depends on the temperature of the supply water and the "thermal mass" of the pad itself.

\section{Prediction of the Operation of the DEC}

In the present paragraph, the sensitivity of a direct evaporative cooler is parameterized and analysed. In this way the effect of each one of the manufacturing and operational parameters of the cooler on the product air temperature is estimated. In order of examination:

- Ambient temperature and relative humidity, for sizes $30^{\circ} \mathrm{C}, 32^{\circ} \mathrm{C}, \ldots, 40^{\circ} \mathrm{C}$ and $0 \%, 20 \%, \ldots, 80 \%$, under constant air flow $1000 \mathrm{~m}^{3} / \mathrm{h}$ and constant pad porosity $370 \mathrm{~m}^{-1}$.
- Air volume flow and ambient temperature, for sizes $500 \mathrm{~m}^{3} / \mathrm{h}, 1000 \mathrm{~m}^{3} / \mathrm{h}, 1500 \mathrm{~m}^{3} / \mathrm{h}, 2000 \mathrm{~m}^{3} / \mathrm{h}, 2500 \mathrm{~m}^{3} / \mathrm{h}$ and $30^{\circ} \mathrm{C}, 32^{\circ} \mathrm{C}, \ldots, 40^{\circ} \mathrm{C}$, under constant relative humidity $30 \%$ and constant pad porosity $370 \mathrm{~m}^{-1}$

- Porosity and ambient temperature, for sizes $250 \mathrm{~m}^{-1}$, $400 \mathrm{~m}^{-1}, 550 \mathrm{~m}^{-1}, 700 \mathrm{~m}^{-1}$ and $30^{\circ} \mathrm{C}, 32^{\circ} \mathrm{C}, \ldots, 40^{\circ} \mathrm{C}$, under constant relative humidity $30 \%$ and constant air flow $1000 \mathrm{~m}^{3} / \mathrm{h}$, and with the assumption that the heat transfer coefficient is kept constant.

In any case, the cooler operates under nominal supply conditions (i.e. the water temperature is equal to the ambient air wet-bulb temperature).

\subsection{Sensitivity towards Ambient Conditions}

Figure 5 shows the variation of the cooled air temperature, while changing the ambient temperature and relative humidity.

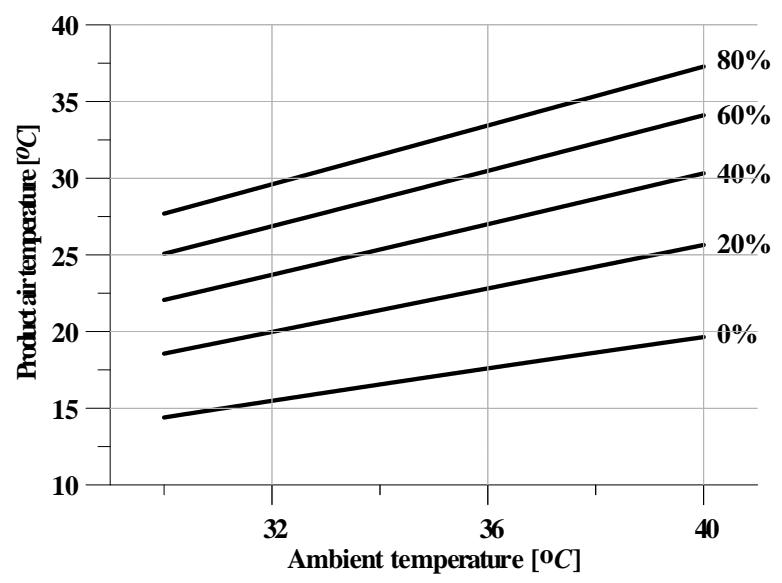

Figure 5. Product air temperature vs. ambient temperature and relative humidity.

The figure clarifies the dependence of the cooled air temperature on the ambient conditions: given the relative humidity, the less hot the supply air, the lower the product air is expected to be similarly, given the ambient temperature, the lower the relative humidity, the lower the product air temperature tends to be. It is confirmed, in this way, that the evaporative coolers provide air which is cooler the drier their ambient is. At this point it is of importance that besides the fact that the air in dry climates is cooled further, and therefore, the numerator in Eq. (1) increases, due to the low wet bulb temperature of the dry air, the denominator in the same equation increases likewise. Consequently, while the dryness of the climate affects the production of cooler air, on the other hand, it does not significantly affect the efficiency of the cooler, as defined in Eq. (1).

\subsection{Sensitivity towards Air Flow}

Figure 6 shows the sensitivity analysis of the cooler towards the air flow for various ambient temperature levels. The results of Figure 6 illustrate that the quantity of the trafficked air does not significantly affect the final air temperature, as the ambient air temperature; in particular, the product air temperature is cooler by $1.5^{\circ} \mathrm{C}$ when the air flow is $500 \mathrm{~m} 3 / \mathrm{h}$, in comparison to the one that appears when the air flow is $2500 \mathrm{~m} 3 / \mathrm{h}$. That is due to the fact that the heat transfer factor kh also increases when the air flow rises, and therefore, the latter causes the increase in the heat transferred from the air to the wet pad. Nevertheless, this 
result is directly linked to the equation which defines the heat transfer factor; it is possible that for another configuration of the pad this factor would behave differently, in a way that the cooled air temperature would be expected to be differently affected.

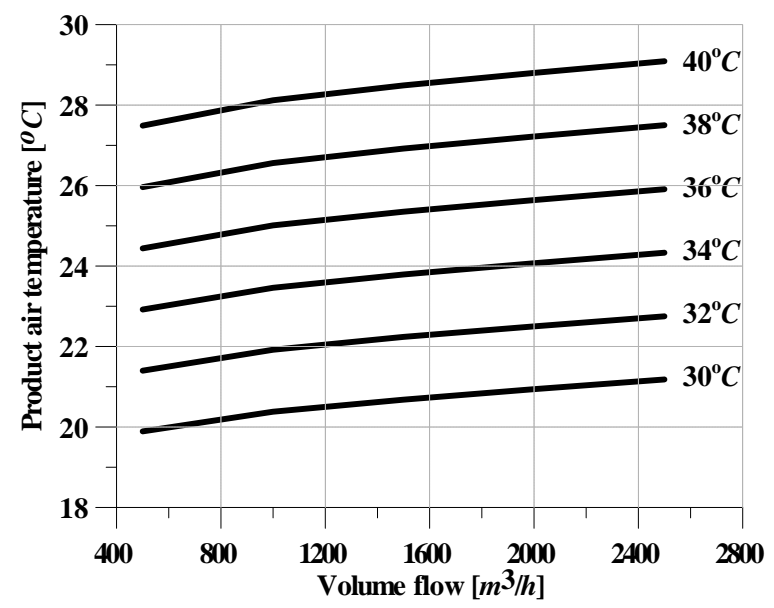

Figure 6. Product air temperature vs. volume flow ambient temperature.

\subsection{Sensitivity Towards the Pad Porosity}

Given the volume of the wet pad, altering the porosity leads to a relevant alternation of the wet surface, and therefore, to an alternation of the transferred water mass from the pad to the air. Under these circumstances, the sensitivity of the cooler towards the porosity is shown in Figure 7.

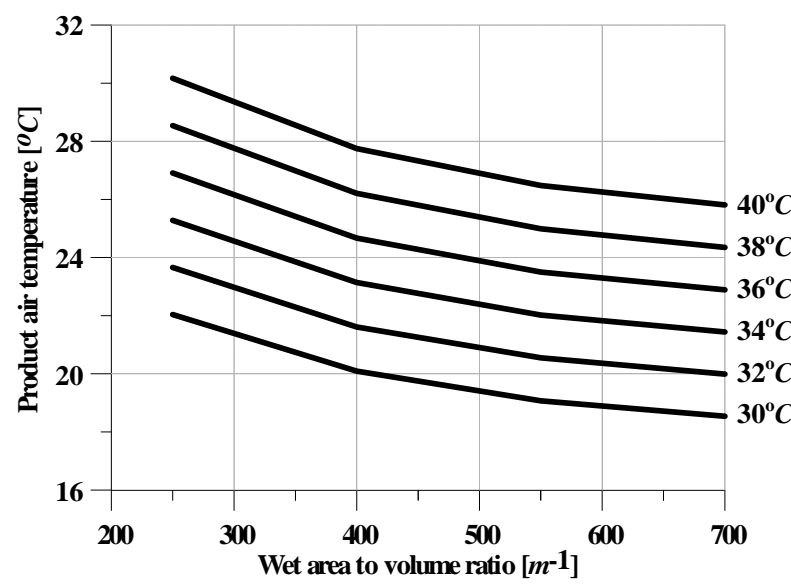

Figure 7. Product air temperature vs porosity.

The correlation between the porosity and the product water temperature becomes obvious: an increase in the pad surface allows the evaporation of a greater amount of water so that the air can be cooled to an even lower temperature. The geometry of the pad is directly related to the efficiency of the cooler, since given the ambient conditions [and constant denominator in Eq. (1)], the increase in the wet surface leads to even higher levels of temperature drop. However, one should not overlook the fact that the increase in the wet surface signifies higher water consumption, which might make the cooler economically uninteresting besides its higher efficiency.

\subsection{Sensitivity of the Efficiency Towards the Air Flow and the Pad Porosity}

Figure 8 shows the variation of the efficiency for constant temperature $35^{\circ} \mathrm{C}$ and relative humidity $30 \%$. It is clear that, as the porosity increases and the volume flow decreases, the efficiency of the cooler tends to be higher; it can be explained by the increased wetted area and the decreased heat and mass transfer coefficients, as they have been defined in Eqs. (9) and (12).

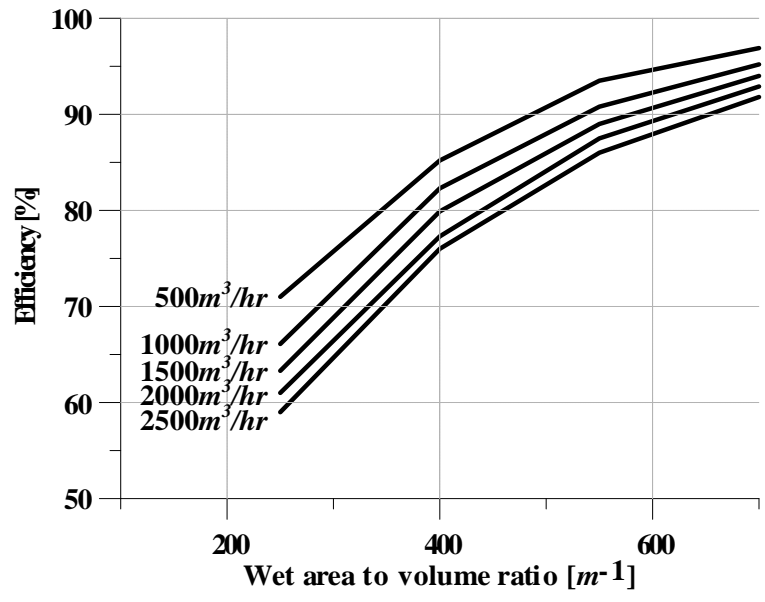

Figure 8. Cooler efficiency vs. porosity and air flow.

6. Estimation of Cooling Capacity and Specific Water Consumption for Various Supply Water Temperatures

The cooling capacity of the cooler for various ambient and supply water conditions are presented in Table 2. Since, in a direct evaporative cooler, the air brought to the airconditioned room differs not only as far as temperature is concerned, but also in humidity, the cooling capacity is not calculated in terms of enthalpy, but according to Eq. (13).

$Q_{C}=c_{p, a} \cdot\left(t_{1}-t_{2}\right) \cdot \dot{m}_{a}$

As expected, the cooling capacity is, given the ambient circumstances, higher for cooler supply water, since, as previously analyzed, the air tends to be further cooled. It is also easy to trace the tendency of the cooling capacity to dry, as the ambient temperature rises (see Figure 4).

Specific water consumption is defined as the amount of water required to be evaporated by an evaporative cooler in order to produce a $k W h_{\mathrm{c}}$. This definition does not include parameters such as the cooler's cooling capacity, its size and the air temperature. The calculation of the specific water consumption results from equation 14 .

$s w c=\frac{\dot{m}_{w}}{Q_{c}}=\frac{\dot{m}_{a} \cdot\left(W_{2}-W_{1}\right) \cdot 3600}{c_{p, a} \cdot\left(t_{1}-t_{2}\right) \cdot \dot{m}_{a}}=\frac{\left(W_{2}-W_{1}\right) \cdot 3600}{c_{p, a} \cdot\left(t_{1}-t_{2}\right)}$

In Table 3 specific water consumption values are shown related to the ambient conditions and the supply water temperatures. 
Table 2. Cooling Capacity.

\begin{tabular}{|c|c|c|c|c|c|c|}
\hline $\mathbf{t}_{\mathbf{1}}$ & $\varphi_{1}$ & $\mathbf{t}_{\mathrm{w}}=\mathbf{t}_{1, \mathrm{wb}}-1.0^{\circ} \mathrm{C}$ & $\mathbf{t}_{\mathrm{w}}=\mathrm{t}_{1, \mathrm{wb}}-0.5^{o} C$ & $\begin{array}{c}\text { Cooling capacity }\left[k W_{c}\right] \\
t_{t_{w}}=t_{1, w b}\end{array}$ & $\mathrm{t}_{\mathrm{w}}=\mathrm{t}_{1, \mathrm{wb}}+0.5^{o} \mathrm{C}$ & $\mathbf{t}_{\mathrm{w}}=\mathbf{t}_{1, \mathrm{wb}}+1.0^{\circ} \mathrm{C}$ \\
\hline $34.3^{\circ} \mathrm{C}$ & $28.2 \%$ & 3.71 & 3.58 & 3.46 & 3.33 & 3.46 \\
\hline $34.6^{\circ} \mathrm{C}$ & $27.8 \%$ & 3.76 & 3.63 & 3.50 & 3.38 & 3.50 \\
\hline $34.7^{\circ} \mathrm{C}$ & $27.3 \%$ & 3.80 & 3.67 & 3.55 & 3.42 & 3.55 \\
\hline $34.8^{\circ} \mathrm{C}$ & $27.4 \%$ & 3.80 & 3.67 & 3.55 & 3.42 & 3.55 \\
\hline $35.0^{\circ} \mathrm{C}$ & $27.2 \%$ & 3.83 & 3.70 & 3.57 & 3.44 & 3.57 \\
\hline $35.1^{\circ} \mathrm{C}$ & $27.3 \%$ & 3.83 & 3.70 & 3.57 & 3.45 & 3.57 \\
\hline $35.2^{\circ} \mathrm{C}$ & $26.9 \%$ & 3.86 & 3.74 & 3.61 & 3.48 & 3.61 \\
\hline $35.3^{\circ} \mathrm{C}$ & $26.6 \%$ & 3.89 & 3.77 & 3.64 & 3.51 & 3.64 \\
\hline $35.6^{\circ} \mathrm{C}$ & $26.6 \%$ & 3.92 & 3.79 & 3.66 & 3.53 & 3.66 \\
\hline $35.9^{\circ} \mathrm{C}$ & $26.0 \%$ & 3.98 & 3.85 & 3.73 & 3.60 & 3.73 \\
\hline $36.2^{\circ} \mathrm{C}$ & $24.8 \%$ & 4.09 & 3.96 & 3.83 & 3.70 & 3.83 \\
\hline $36.3^{\circ} \mathrm{C}$ & $24.6 \%$ & 4.11 & 3.98 & 3.85 & 3.73 & 3.85 \\
\hline $36.4^{\circ} \mathrm{C}$ & $24.7 \%$ & 4.11 & 3.98 & 3.85 & 3.73 & 3.85 \\
\hline $36.7^{\circ} \mathrm{C}$ & $24.2 \%$ & 4.17 & 4.04 & 3.91 & 3.79 & 3.91 \\
\hline $36.9^{\circ} \mathrm{C}$ & $23.6 \%$ & 4.23 & 4.10 & 3.97 & 3.84 & 3.97 \\
\hline $37.2^{\circ} \mathrm{C}$ & $24.2 \%$ & 4.21 & 4.08 & 3.96 & 3.83 & 3.96 \\
\hline $37.4^{\circ} \mathrm{C}$ & $23.5 \%$ & 4.28 & 4.15 & 4.02 & 3.90 & 4.02 \\
\hline \multicolumn{2}{|c|}{ Average value } & 3.98 & 3.85 & 3.72 & 3.59 & 3.72 \\
\hline \multicolumn{2}{|c|}{ Average deviation } & $+6.8 \%$ & $+3.5 \%$ & - & $-3.5 \%$ & $-6.8 \%$ \\
\hline
\end{tabular}

It can be concluded that ambient conditions do not effect specific water consumption to the extent that the supply water temperature can; in particular, the typical derivation from average values of consumption, which are displayed in Table 3 does not exceed 0.17 , which is due to the fact that water temperature tends to cool the product air further or less (alternating in this way the cooler's cooling capacity), so that the denominator of equation 14 can increase or decrease respectively. In contrast, the effect of the water temperature is of major significance, since supplying the cooler with water cooled by $1{ }^{\circ} \mathrm{C}$ of the nominal reduces the specific water consumption by roughly $21 \%$, while water hotter by $1{ }^{\circ} \mathrm{C}$ increases it by roughly $25 \%$.

\section{Conclusions}

In this paper an energy model was developed for the simulation of direct evaporative coolers, allowing the prediction of the behaviour of such systems under any working/ operating conditions. The model was executed for various ambient conditions and the effect of the supply water temperature on the product air temperature was tested; the final conclusion was that related to the nominal supply condition (where the water temperature is equal to the ambient wet bulb temperature) by any chance cooler or hotter water would further reduce or not allow the total nominal temperature drop inside the cooler.

The sensitivity of the cooler towards 5 different parameters was also examined. Besides ambient and supply conditions, the functional parameter of the air flow (related to which a weak relationship to the final air temperature was grounded, due to the heat transfer factor behaviour) and the constructional parameter of the pad porosity were added. The latter has a vital effect on the cooler's geometry, altering the available air-water interface and it was confirmed that the bigger that interface the better the cooler efficiency and the final air temperature.

In operational/ functional terms of the direct evaporative cooler, it was shown that the derivation of the supply water temperature from the nominal is always favourable (both of the efficiency and the consumption) when water is cooler than the nominal and vice versa; in particular, just $1^{\circ} \mathrm{C}$ cooler or hotter water can increase or reduce specific water consumption by a percentage above $20 \%$, which should be accordingly considered when sizing an evaporative system, since water is not always abundant or should not be consumed in inefficient forms/systems.

Table 3. Specific Water Consumption.

\begin{tabular}{|c|c|c|c|c|c|c|}
\hline \multirow{2}{*}{$\mathbf{t}_{1}$} & \multirow[b]{2}{*}{$\varphi_{1}$} & \multicolumn{5}{|c|}{ Specific water consumption $\left[\mathrm{kg}_{\mathrm{w}} / \boldsymbol{k W h} \mathrm{c}\right]$} \\
\hline & & $\mathbf{t}_{\mathrm{w}}=\mathbf{t}_{1, \mathrm{wb}}-1.0^{\circ} \mathrm{C}$ & $\mathbf{t}_{\mathrm{w}}=\mathbf{t}_{1, \mathrm{wb}}-0.5^{o} \mathrm{C}$ & $\mathbf{t}_{\mathrm{w}}=\mathbf{t}_{1, \mathrm{wb}}$ & $\mathbf{t}_{\mathrm{w}}=\mathrm{t}_{1, \mathrm{wb}}+0.5^{\circ} \mathrm{C}$ & $\mathbf{t}_{\mathrm{w}}=\mathbf{t}_{1, \mathrm{wb}}+1.0^{\circ} \mathrm{C}$ \\
\hline $34.3^{\circ} \mathrm{C}$ & $28.2 \%$ & 1.153 & 1.321 & 1.500 & 1.694 & 1.901 \\
\hline $34.6^{\circ} \mathrm{C}$ & $27.8 \%$ & 1.162 & 1.327 & 1.504 & 1.696 & 1.901 \\
\hline $34.7^{\circ} \mathrm{C}$ & $27.3 \%$ & 1.185 & 1.319 & 1.494 & 1.682 & 1.884 \\
\hline $34.8^{\circ} \mathrm{C}$ & $27.4 \%$ & 1.159 & 1.323 & 1.497 & 1.686 & 1.888 \\
\hline $35.0^{\circ} \mathrm{C}$ & $27.2 \%$ & 1.169 & 1.331 & 1.506 & 1.693 & 1.894 \\
\hline $35.1^{\circ} \mathrm{C}$ & $27.3 \%$ & 1.172 & 1.334 & 1.509 & 1.695 & 1.897 \\
\hline $35.2^{\circ} \mathrm{C}$ & $26.9 \%$ & 1.188 & 1.319 & 1.491 & 1.675 & 1.874 \\
\hline $35.3^{\circ} \mathrm{C}$ & $26.6 \%$ & 1.166 & 1.325 & 1.497 & 1.681 & 1.877 \\
\hline $35.6^{\circ} \mathrm{C}$ & $26.6 \%$ & 1.170 & 1.329 & 1.500 & 1.681 & 1.878 \\
\hline $35.9^{\circ} \mathrm{C}$ & $26.0 \%$ & 1.169 & 1.326 & 1.492 & 1.671 & 1.862 \\
\hline $36.2^{\circ} \mathrm{C}$ & $24.8 \%$ & 1.192 & 1.345 & 1.508 & 1.682 & 1.868 \\
\hline $36.3^{\circ} \mathrm{C}$ & $24.6 \%$ & 1.193 & 1.345 & 1.506 & 1.680 & 1.864 \\
\hline $36.4^{\circ} \mathrm{C}$ & $24.7 \%$ & 1.195 & 1.347 & 1.509 & 1.683 & 1.867 \\
\hline $36.7^{\circ} \mathrm{C}$ & $24.2 \%$ & 1.189 & 1.338 & 1.497 & 1.666 & 1.849 \\
\hline $36.9^{\circ} \mathrm{C}$ & $23.6 \%$ & 1.207 & 1.355 & 1.484 & 1.651 & 1.859 \\
\hline $37.2^{\circ} \mathrm{C}$ & $24.2 \%$ & 1.188 & 1.335 & 1.493 & 1.660 & 1.871 \\
\hline $37.4^{\circ} \mathrm{C}$ & $23.5 \%$ & 1.215 & 1.335 & 1.489 & 1.654 & 1.861 \\
\hline & rage value & 1.181 & 1.333 & 1.499 & 1.678 & 1.876 \\
\hline & deviation & $-21.2 \%$ & $-11.1 \%$ & - & $+11.9 \%$ & $+25.2 \%$ \\
\hline
\end{tabular}




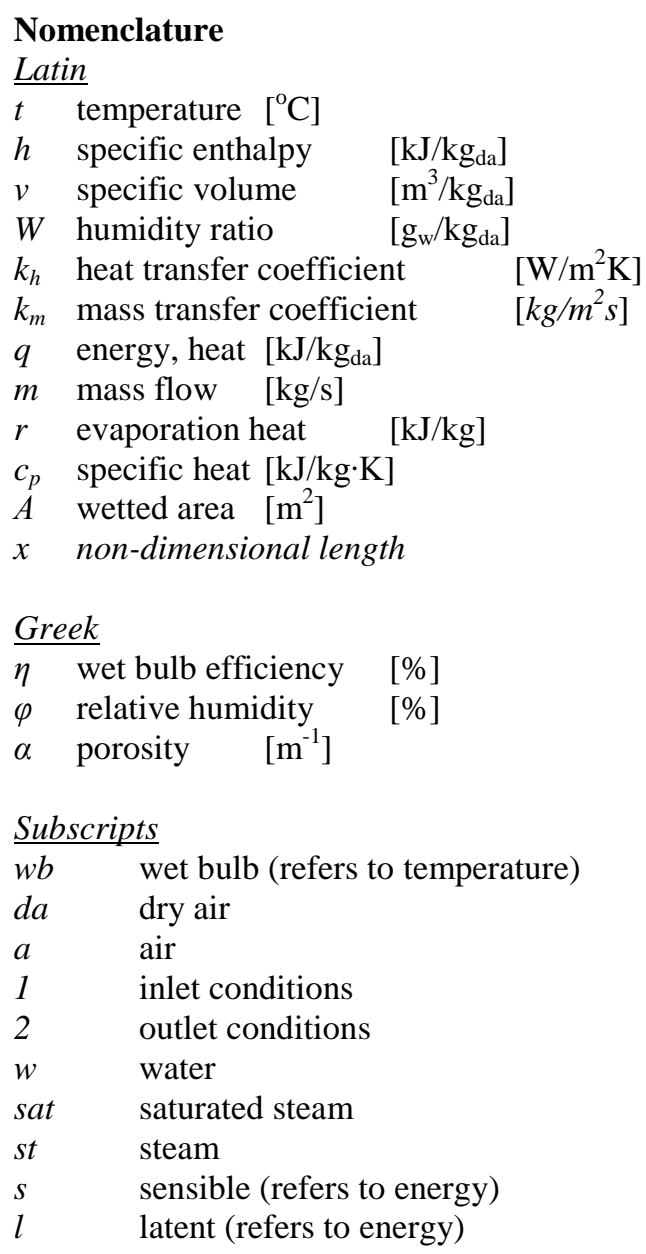

\section{References}

Camargo, J. R., Ebinuma, C. D., Silveira, J. L. (2005). Experimental performance of a direct evaporative cooler operating during summer in a Brazilian city. International Journal of Refrigeration, 28, 1124-1132.

Erens, P.J., Dreyer, A.A. (1991). Modelling of indirect evaporative air coolers. International Journal of Heat and Mass Transfer, 36, 17-26.

Fouda, A., Melikyan, Z. (2011). A simplified model for analysis of heat and mass transfer in a direct evaporative cooler. Applied Thermal Engineering, 31, 932-936.

Finlay, I. C., Harris, D. (1984). Evaporative cooling of tube banks. International Journal of Refrigeration, 7, 214224.

Kachhwaha, S. S., Prabhakar, S. (2010). Heat and mass transfer study in a direct evaporative cooler, Journal of Scientific \& Industrial Research, 69, 705-710.

Lazzarin, R. (2007). Introduction of a simple diagram-based method for analyzing evaporative cooling. Applied Thermal Engineering, 27, 2011-2025.

Perry's Chemical Handbook (Vol. 7) (2008). New York: McGraw-Hill Companies, Chapter 2, pp. 60.

Wu, J.M., Huang, X., Zhang, H. (2009). Numerical Investigation on the heat and mass transfer in a direct evaporative cooler, Applied Thermal Engineering, 29, 195-201.

Papaefthimiou, V. D. (2004). Thermodynamic Analysis of Absorption Engines (Ph.D. thesis), National Technical University of Athens, Thermal Engineering Department. 